ENTREVISTA

\title{
A MÁQUINA DE CULTURA: DE GEERTZ A HOLLYWOOD
}

Sherry Ortner

Membro da American Academy of Arts and Sciences e atualmente Distinguished Professor of Anthropology na Universidade da Califórnia, Sherry Ortner é um dos nomes mais importantes da antropologia americana contemporânea, notadamente nas áreas da teoria e da crítica cultural. Aluna de David Schneider e de Clifford Geertz em Chicago, nos anos 1960, fez trabalho de campo entre os Sherpa do Nepal, focalizando principalmente os temas da religião e da política. A partir dos anos 1970, Ortner destacou-se no contexto da antropologia feminista, campo que ajudou a consolidar, sobretudo por situar o estudo das relações de gênero e da dominação masculina no âmbito das análises culturais voltadas para questões de significado e valor. Sua produção posterior inclui uma apropriação crítica da teoria da prática, da qual se diz entusiasta, de modo a fazê-la dialogar com perspectivas analíticas minoritárias e subalternas, um projeto que implicaria pensar a questão do poder e da dominação sem abrir mão da intencionalidade do sujeito. Mais recentemente, seu interesse voltou-se para a sociedade americana, em particular para os significados e os efeitos das noções de "geração" e de "classe social" nos Estados Unidos.
Em 2006, a convite da Associação Brasileira de Antropologia, Ortner participou da XXVa Reunião Brasileira de Antropologia, realizada em Goiânia. Esteve também em São Paulo e no Rio de Janeiro, onde concedeu esta entrevista a Carlos Fausto e a Cristiane Lasmar. Em estilo coloquial e contundente, ela rememora aqui sua trajetória acadêmica e sua experiência etnográfica, refletindo sobre conceitos centrais de seu trabalho, tais como cultura, agência, prática, poder e dominação.

Também evoca, de maneira muito vívida, o contexto social e político ao qual estiveram inextricavelmente ligados os desenvolvimentos da antropologia americana após os anos 1960, em particular aqueles relativos à noção de cultura - noção, aliás, da qual, a seu ver, a antropologia não pode prescindir inteiramente. Entrevistadores: Carlos Fausto e Cristiane Lasmar. Transcrição: Thaddeus Blanchette. Tradução: Amir Geiger. Revisão: Carlos Fausto e Cristiane Lasmar 
CF: Gostaríamos de começar por uma nota de rodapé que você escreveu em The fate of culture ${ }^{1}$, falando de Geertz. Você diz: "Levou algum tempo para perceber quão profundamente eu estava marcada pela sua perspectiva, em parte, através de sua influência direta, mas ainda mais pelo impacto que o seu pensamento teve sobre o programa de pós-graduação em Chicago, e quão fortemente o programa de pós-graduação de Chicago, por sua vez, impunha-se aos estudantes". Você poderia nos falar sobre Chicago nos anos 60 ?

Acho que provavelmente não é diferente agora. Era mesmo muito intenso. Havia o sentimento de estar no centro do universo: de ter o melhor departamento, os colegas mais inteligentes, os melhores professores. Havia essa sensação formidável (provavelmente um tanto exagerada) de que era a coisa mais maravilhosa do mundo. Havia também uma sensação de que você tinha que realmente ser bom. B+ não era bastante bom. Eu tinha estudado num curso de graduação bem difícil, um college feminino chamado Bryn Mawr, que também era muito bom. Eu exultava com os B+ em Bryn Mawr e, quando cheguei a Chicago, recebi B+ no primeiro trabalho. Achei que tinha ido bem. Aí percebi que esta era a nota mais baixa no sistema. Tínhamos também certa sensação de sermos os "donos da verdade", de que o tipo de antropologia ensinado em Chicago era a verdadeira e única antropologia. Havia naquele tempo uma grande polarização: éramos "nós" (os interpretativistas, produzindo uma antropologia interpretativa rica e complexa) contra os materialistas vulgares, que predominavam na Universidade de Michigan e também em Columbia. Eles eram uma espécie de "Império do Mal" e nós éramos os mocinhos, os que tinham tido a revelação. Embora meu próprio trabalho tenha passado por muitas mudanças em termos desta oposição, mesmo agora, olhando para trás, percebe-se que Geertz estava mesmo trazendo algo novo. Era realmente um momento radical na antropologia, um momento de reescritura da disciplina. E isso era parte da graça, embora eu não o percebesse bem na época.

CF: Mas o que você quer dizer exatamente com "impondo-se aos alunos"?

Quando saí da pós-graduação e comecei a fazer o que considero meu próprio trabalho, percebi que estava exatamente cumprindo a agenda de Chicago. E aí, retomando contato com colegas, com minha turma de Chicago (nós nos tínhamos dispersado e durante algum tempo eu não os vira nem os lera), percebi, de repente, que estávamos todos fazendo a mesma coisa. Por mais que pensássemos estar fazendo algo diferente ou original, só cumpríamos uma espécie de agenda estabelecida em Chicago. Era preciso de algum modo compreender este fato para poder superá-lo, para poder ir adiante e começar a fazer alguma coisa nova. Era preciso primeiro dar-se conta do grau em que se estava praticando determinada agenda, para então ir além dela - e espero tê-lo conseguido.

CL: Quem eram seus professores e colegas de turma?

Pelo que sei, o departamento havia acabado de contratar Geertz, Schneider e um africanista chamado Lloyd Fallers (de Berkeley). E esta foi a grande mudança.

CF: Turner não estava lá, naquela época?

Não. Os Turners chegaram quando eu estava no campo. Não os conheci quando 
era aluna, eles vieram um pouco depois. Geertz, Schneider e Fallers eram muito ligados. Geertz e Schneider tinham feito juntos a pós-graduação em Relações Sociais, em Harvard, e haviam estudado com Talcott Parsons. Eles refizeram todo o programa de pós-graduação em Chicago. Por isso, criaram o curso "Sistemas", que ainda está lá.

\section{CL: Como funcionava, então?}

Era um regime trimestral. No primeiro trimestre, tínhamos "Sistemas Sociais", que era sobre antropologia social britânica. No segundo, "Sistemas Culturais", era Geertz, bem como Ruth Benedict, Margaret Mead, a velha tradição americana. E o terceiro trimestre era dividido ao meio: metade era sobre sistemas psicológicos - o modelo parsoniano - e a outra metade, antropologia lingüística. Tudo isso em paralelo com outro curso chamado "O percurso humano". Tínhamos Clark Howell, para o Paleolítico; Lewis Binford, para o Mesolítico; e Bob Adams, ${ }^{2}$ para o Neolítico.

\section{CL: Geertz já era o seu orientador?}

$\mathrm{Na}$ verdade, quando me inscrevi em Chicago, eu disse que estava interessada no Pacífico. Então me encaminharam para David Schneider. Ele era, em determinado plano, uma pessoa gentil, mas em outro, um orientador bem difícil (e, creio, também difícil como colega). Schneider me enlouquecia, embora eu ache que ele dava tudo de si e que eu era muito ignorante. O trabalho dele me parecia estranho. Eu não compreendia o que ele estava tentando fazer mas, em retrospecto, era uma espécie de perspectiva desconstrutivista. Na época, porém, parecia-me apenas um tipo de versão muito estranha de estruturalismo. Mas eu gostaria de dizer que Schneider tinha uma coisa muito boa: ele protegia os alunos que queriam fazer algo diferente, como trabalhar nos EUA, o que não era muito aceitável, então. Ele defendeu Esther Newton, que queria estudar drag queens, assim como defendeu outros alunos que queriam estudar a cultura jovem americana. Schneider era bom nisso.

CF: Na época, ele estava escrevendo American kinship ${ }^{3}$, não é?

Ele estava tomado por American kinship. Na verdade, isso é que me salvou, porque eu queria fugir dele, mas tinha medo. Como ele estava com problemas para terminar o livro, tirou uma licença de um ano. Ele disse a todos os orientandos que procurassem outros orientadores, que ele queria terminar o livro e não ia orientar ninguém durante a licença. Eu fiquei muito contente, porque estava liberada. Escrevi para Geertz, que estava no Marrocos, perguntando se ele gostaria de ser meu orientador. E ele aceitou.

\section{CL: Você chegou a comentar isto com} Schneider?

Bem, tempos depois nós ficamos amigos. E eu soube que o que aconteceu foi o seguinte: ele mandou a mesma carta para todos os orientandos, mas alguns insistiram em continuar com ele, e ele aceitou. Eu não; eu estava feliz em ser liberada. Anos mais tarde, ele me perguntou se eu o tinha deixado por causa da carta e eu disse "Sim, é claro!". E ele me respondeu que se arrependia de tê-la escrito. Esta é a história.

CF: Mas no fim das contas ele deixou uma marca forte no seu trabalho, não é verdade? Toda a idéia de um símbolochave, que você aplicou para ler a teoria antropológica, era basicamente de Schneider, certo? 
Obviamente tinha conexão com isso, mas eu não me via tomando-a de Schneider. $\mathrm{Na}$ verdade, me via tomando-a em parte de Benedict, mas também de outra linhagem. Por incrível que pareça, de Evans-Pritchard. Ele não usou o termo "símbolo-chave", mas fala do gado na cultura dos Nuer como uma espécie de símbolo-chave para eles. Talvez, porém, eu tenha inconscientemente tirado isso de Schneider, embora não me visse recorrendo a ele.

CF: Você se referiu aos seus colegas de turma em Chicago. Quem eram eles?

Éramos uma turma muito grande. Admitiram uns 50 alunos no meu ano. Eles aceitavam um grande número de alunos sem financiamento, e a pessoa tinha que pagar a anuidade do primeiro ano, no final do qual havia vários exames. Muito difíceis. Ficava-se sentado por cinco horas fazendo prova de "sistemas" e cinco horas na prova de "percurso humano". Era preciso passar com notas altas nas duas provas para seguir no doutorado, sem negociação com os orientadores: cada aluno recebia um número, não havia nome nas provas, que eram avaliadas por bancas. Eles levavam isto a sério. E era muito bom para as mulheres, porque anulava o sexismo padrão do sistema. Acho que era acidental. Fizeram desse modo por não quererem membros do corpo docente favorecendo alunos. Eles nem pensavam em sexismo nos anos 60. Mas, de qualquer modo, só nove pessoas conseguiram dupla aprovação com nota alta na primeira rodada, e dessas nove, sete eram mulheres.

\section{CL: Então somente nove passaram para o doutorado?}

Não, as pessoas fizeram novas provas. No fim, acho que 25 pessoas, das 50, fizeram o doutorado; ou seja, tenho uma rede de 25 pessoas do meu ano, sem falar que eu era amiga de gente do ano anterior e do ano seguinte. Penso, assim, que além de tudo o mais, foi simplesmente o tamanho em si dessa rede que acabou tendo muito impacto.

\section{CL: E quanto às pessoas?}

Bem, Ellen Basso era da minha turma, assim como Bobby Paul, meu ex-marido, que agora é decano na Universidade de Emory. Também Harriet Whitehead, com quem colaborei, Karen Blu, que trabalhou com índios da América do Norte. Harriet, Karen e eu viemos juntas da graduação e éramos chamadas em Chicago de "a máfia de Bryn Mawr". Na turma à minha frente estavam Alfonso Ortiz, Martin Silverman, Esther Newton, Waud Kracke...

\section{CF: Roy Wagner era da turma que entrara dois anos antes?}

Acho que sim. Não o conheci na pós-graduação. Paul Rabinow entrou dois anos depois, e eu o conhecia um pouco porque ele estava sempre por ali. Ele tinha sido aluno de graduação em Chicago. Quando concluímos o curso da pós-graduação, Bobby e eu fomos morar em Nova York e várias outras pessoas também. Paul Rabinow, que era nova-iorquino, voltou para a sua cidade. E assim acabamos formando um grupo grande lá e criamos "O Seminário de Chicago em Nova York". O grupo montou uma mesa para o encontro de 1972 ou 1973 da AAA [American Anthropological Association], que viria a lançar a antropologia simbólica. Éramos oito do grupo e Clifford Geertz como debatedor. Foi uma coisa impactante. A sala estava lotada; era o momento de anunciar a antropologia simbólica para a disciplina. 
CL: Vamos passar do contexto intelectual para o político. Qual era a sua relação com os movimentos radicais daquele período?

Bem, eu fiz pós-graduação de 1963 a 1970. No início, ou não estava acontecendo muita coisa, ou eu não prestei atenção. Havia o movimento pelos Direitos Civis e eu participei um pouco quando fazia graduação, mas quando entrei para a pós, fiquei focada nos estudos. Fui para o campo em 1966 e deu-se então o estouro da contracultura at home. As pessoas me escreviam sobre isso e recebíamos, no campo, a Newsweek Asia. Naquele mesmo ano também, refiro-me principalmente a 1967, houve todos aqueles conflitos raciais, inclusive na minha cidade, Newark, em Nova Jersey. Foi enquanto eu estava fora que tudo começou a explodir. Quando voltamos, percebi de imediato que algo importante estava acontecendo. O movimento contra a guerra do Vietnã havia começado. Fiquei meio perplexa. Também visualmente, os estilos... os homens de cabelos compridos... Quando saí eram os anos 50, quando voltei já eram os anos 60. Até os filmes eram diferentes. Eu não conseguia entender. Todo mundo dizia: "Você precisa ver The graduate"4 com Dustin Hoffman. Eu fui ver o filme e não entendi do que se tratava. Então me disseram: "Você tem que ver Bonnie and Clyde" ${ }^{\prime 5}$ e eu fui ver, e achei que realmente era um filme bastante bom, mas não entendia por que todo mundo o considerava tão importante.

\section{CL: E aí você foi atraída pela política...}

Eu me senti atraída pela política, mas tinha que escrever a tese. Havíamos mudado para Nova York. Lembro que ia todo dia à Universidade de Columbia para trabalhar na biblioteca. Um dia, em 1969, os estudantes radicais comemoravam na universidade o aniversário da revolta de 68. Eu, na biblioteca, tentando escrever; era primavera, as janelas abertas, e as pessoas fazendo uma manifestação nas escadas da Low Library, que é uma espécie de praça central de Columbia. Eu queria estar lá embaixo, mas tinha que terminar a tese. Na verdade, foi bom ter saído de Chicago. Eu e Bobby podíamos nos dedicar à tese, enquanto a maioria dos meus amigos tinha que participar de um seminário pós-trabalho de campo: todos traziam capítulos para apresentar e ter algum retorno - retorno até demais para quem está escrevendo uma tese. Fomos os primeiros a terminar, porque estávamos longe de Chicago e ninguém nos dizia o que fazer. Assim, escrevi uma tese ruim, mas ficou pronta, e isso era o principal.

\section{CL: Em que momento você começou a se envolver com o feminismo?}

Eu não me envolvi imediatamente em quase nada do que estava acontecendo, mas em 1970, um ano depois, Michelle Rosaldo e Louise Lamphere organizaram uma sessão para o encontro da AAA em Toronto e me convidaram a apresentar algo. Eu disse que não sabia nada sobre mulheres. E elas responderam: “Ninguém sabe nada sobre mulheres. Nós vamos inventar". Eu não tinha dados, porque não pesquisava sobre mulheres, não estudava gênero. Eu ainda estava na escola antiga. Então tive que fazer algo teórico, e escrevi "Is female to male as nature is to culture?". ${ }^{6}$ Foi a segunda coisa que publiquei em toda a minha carreira.

CF: Qual era na época a sua relação com o marxismo?

Bem, saímos de Chicago com essa abordagem interpretativista e humanista da antropologia, e com uma noção muito simplificada do que era o marxismo. 
Marvin Harris tinha proclamado que ele era um materialista não-dialético, o que era, na verdade, um materialismo burguês. Não era o marxismo, era um materialismo completamente reducionista. Era por isso que considerávamos, corretamente, que eles não produziam boa antropologia e, claro, talvez nem mesmo fizessem boa política. Mas é preciso distinguir gente como Eric Wolf e Marshall Sahlins, que faziam um tipo sério de marxismo em Michigan, embora a posição de Marshall fosse mais intermediária. Acho que pessoas como eu começaram a buscar uma integração entre o quadro marxista dos "bad guys" e o quadro meio weberiano com que fôramos alimentados em Chicago. Se você olhar para a assim chamada antropologia simbólica, o que ocorreu é que alguns foram na direção de certo marxismo, e outros foram para uma perspectiva muito literária, afastandose ainda mais do mundo material e das questões materiais.

CF: Você diria que esta é uma antropologia aristocrática?

Eu realmente me esforço muito para não cair nesse tipo de polarização. Estou sempre atenta para as convergências interessantes entre as coisas. Acho que aquela é, em parte, uma perspectiva problemática, mas também sei que eles se vêem produzindo um tipo de antropologia crítica. Na minha opinião, eles se afastam das questões importantes. Se eu disser que eles são muito conservadores (como me parecem ser), eles obviamente discordarão veementemente. Então, acho que vou me esquivar.

CL: Vamos falar dos Sherpas. Você poderia contar a sua experiência no campo?

Bem, o trabalho de campo foi, de certo modo, maravilhoso, mas muito difícil - fisicamente, e também pelo isolamento. Quanto à substância do projeto, eu provavelmente fazia algo na linha dos símbolos-chave, sobre os quais escrevi depois. Mas quando voltei, no início dos anos 1970, com todos aqueles acontecimentos políticos, eu tive que rever o meu material e tentar atualizá-lo. Então, The Sherpas through their rituals, ${ }^{7}$ o primeiro livro, foi menos uma tentativa de fazer uma espécie de leitura cultural pura e neutra daqueles rituais do que uma leitura crítica em termos do que eu via como tensões e contradições na cultura e na sociedade.

\section{CL: Por quanto tempo você esteve no campo?}

Para o primeiro projeto, fiquei 14 meses, e voltei tão esgotada que pensei que talvez não tornasse a fazê-lo. Mas fui chamada para fazer um filme para a Granada Television, e voltei em 1976, com a equipe de filmagem de $A$ disappearing world, sobre os Sherpas. O projeto do filme foi um pouco mais fácil. Primeiro, porque tínhamos mais dinheiro, logo, eu tinha mais conforto. Em segundo lugar, eu sabia o que esperar e já estava mais velha e mais experiente. Foi também um pouco tranqüilizador, no sentido de que, retornando, pude dar prosseguimento a coisas que tinha investigado na primeira vez, mas que não estava certa de ter entendido bem; indaguei novamente as pessoas, para saber se minha compreensão fora correta, e tive algumas confirmações. Isto fez com que eu me sentisse melhor em relação ao primeiro projeto.

\section{CL: Depois do filme, você ainda voltou para a regiáo?}

Depois do filme, escrevi High religion. ${ }^{8}$ Que também deu certo, acho que não só por causa das coisas que já mencionei, 
mas porque o projeto fazia sentido para os Sherpas. Eu disse: "Vou coletar todas as suas tradições, as velhas histórias, vou falar com os mais velhos sobre o que aconteceu no passado, sobre a fundação desses templos e monastérios", tudo do ponto de vista deles... E isto fazia mais sentido, se comparado ao meu primeiro projeto, que era mais como "Fale-me sobre a sua cultura", o que não fazia sentido para ninguém.

CF: Você dedicou High religion ao assistente Sherpa que morreu antes de o livro ser publicado. Life and death on Mount Everest ${ }^{9}$ é sobre a relação entre os montanhistas ocidentais e os Sherpas - relação que é assimétrica. Como você vê o seu relacionamento com os Sherpas?

Eu acho que melhorei com o tempo. Eu morro de vergonha ao pensar no meu primeiro trabalho de campo, porque sinto que realmente nós não tínhamos autoconsciência ou reflexividade. Como a maior parte da velha antropologia, só funcionou porque as pessoas são legais. Elas diziam "OK, aqui estão esses americanos tolos, não sabem nada, mas têm boas intenções. E além do mais, não custa nada...". E assim por diante. Então, penso realmente que a antropologia funcionou durante décadas porque as pessoas são legais, e não porque se fizesse a coisa certa ou porque elas tivessem alguma percepção das nossas verdadeiras intenções. Acho que isso foi evoluindo aos poucos, porque eu tentava alinhar mais e mais os meus interesses com aquilo que os interessava. Foi esse tipo de alinhamento que se deu de modo geral no trabalho de campo antropológico. Agora, com relação ao Sherpa a quem dediquei o livro, Nyima Chotar, ele de fato gostava desse tipo de trabalho. Ele era uma espécie de intelectual nativo, e acho que se encontram pessoas assim em qualquer lugar. Você dá sorte, como antropóloga, quando os encontra e eles encontram você, e as coisas dão certo.

CF: Deixe-me fazer uma pergunta sobre a condição de gênero no campo. Bruna Franchetto $^{10}$ relata que se sentia numa espécie de condição andrógina. Por um lado, sexualmente falando, era mulher; por outro, era uma não-nativa e, nesse sentido, alguém poderoso, uma espécie de "homem". Em certas situações, era tratada como homem, tinha acesso a espaços que são proibidos às mulheres, e assim por diante. Você experimentou no Nepal esse tipo de condição andrógina?

Isso foi mudando nas diversas viagens. Acho que, em geral, sim, as mulheres ocidentais estão numa categoria separadanão só andróginas, mas poderosas. Os Sherpas têm uma cultura masculina razoavelmente não-agressiva. Assim, nesse sentido, mesmo antes de dizer respeito à minha própria condição, tudo isso tem a ver com o modo com que eles operam. Os homens não são muito predatórios em relação às mulheres em geral. Além disso, na minha primeira viagem, eu estava com Bobby Paul e éramos um casal. Eu era, portanto, uma mulher casada e não percebi até que ponto este podia ser um fator relevante, até voltar sozinha, na viagem seguinte, quando de fato senti no ar algo que era com certeza de caráter sexual. Eu estava solteira e, novamente, ninguém foi agressivo, mas havia a percepção de que eu era mulher, que homens eram homens, e algo poderia acontecer, esta era agora uma possibilidade aberta. Mas depois disso já fui ficando mais velha, o que de certo modo voltou a tirar o assunto da pauta.

CF: Mudando de assunto, de que modo se modificou, ao longo da sua trajetória intelectual, a relação com o conceito de cultura? 
Bem, minha sensação é a de que eu nunca o abandonei. Quer dizer, mesmo quando me envolvi com a teoria marxista, a teoria da prática e o feminismo, ainda me parecia que o conceito básico, geertziano (o que significa dizer: americano) de cultura é indispensável. Continuamos a precisar dele como conceito. Mas é necessário pensar sobre o que fazer com ele, pois ele acarreta problemas políticos e também intelectuais. Não podemos prescindir de algum tipo de conceito de cultura, no sentido de um quadro duradouro de disposições, modos de ver, modos de pensar. O campo não pode abrir mão do conceito na medida em que mesmo aqueles que o atacam o fazem entrar sorrateiramente pela porta dos fundos. Eu brinco com minha amiga Lila Abu-Lughod porque ela escreve contra a cultura, mas quando usa a noção de "mundos", como em "mundos de mulheres", parece-me que é apenas outro modo de contrabandear de volta a cultura. Obviamente, estou ciente de que ela muda a linguagem para tentar escapar de certas implicações problemáticas do conceito de cultura.

\section{CF: Que são...?}

Essencialismo e homogeneização do grupo, e também certo tipo de duração, como na idéia de imutabilidade - estas três coisas. A questão é como se livrar desses problemas e ainda manter algum tipo de conceito de cultura. Na verdade, o conceito de cultura vem evoluindo em resposta a tais questões, e trata-se de compreender essas novas formas de pensar sobre a cultura. Em parte, isto provém de duas áreas. Uma, britânica, a dos estudos culturais - Stuart Hall, Raymond Williams, Paul Willis, Angela McRobbie etc. - com um conceito de cultura ou de hegemonia meio "gramscizado". Outra, dos EUA, basicamente a partir de Appadurai, da revista Public Culture, com todo o deslocamento para a idéia de uma cultura que não reside em grupos particulares, mas que tem uma natureza pública com a qual os diferentes grupos articulam-se de modos diversos. Ou seja, em que há uma relação mais frouxa entre cultura pública e, digamos, o modo mais cotidiano com o qual as pessoas vêem o mundo. Com estas duas abordagens, é possível escapar ao essencialismo e acolher uma relação mais negociada entre pessoas, grupos, setores de grupos, formações culturais. Então, penso que pôr a cultura em questão implica tanto um olhar mais crítico sobre o conceito, como aceitar uma relação mais frouxa entre a cultura e a vida das pessoas.

\section{CL: Como você vê a relação entre feminis-} mo e teoria antropológica? De que modo as reflexões feministas afetaram os seus movimentos teóricos, particularmente o engajamento crítico com a teoria da prática?

De certo modo, a introdução a Making gender $^{11}$ é o núcleo teórico disso. Pois quanto ao meu trabalho empírico, é claro que, depois dos anos 1970, não havia absolutamente como fazer qualquer coisa sem um olhar para as questões de gênero. Mas no nível da teoria, penso que há vários problemas relevantes. Um deles é o de realmente trazer, para a teoria da prática, a teoria crítica do gênero, para dar, digamos assim, uma sacudida na primeira; outro, é o de continuar a colocar questões de gênero, mas com o enquadramento da teoria da prática. Em outras palavras, situar-se em um conjunto de questões de gênero e aí importar aquilo de que se necessita, seja teoria da prática ou qualquer outra coisa. Quer dizer, trata-se de manter uma atitude eclética para tentar resolver controvérsias relativas ao gênero. Creio, então, que 
há hoje uma relação frouxa entre aquilo que se dá na teoria geral (digamos assim) e na produção acadêmica feminista. A teoria feminista tem seu próprio leque de discussões a respeito das quais tenho minhas impressões pessoais. O tipo de predominância que tem Judith Butler, por exemplo, de meu ponto de vista, não é satisfatório, mas esta é a situação real, assim como ocorre com Said e Spivak nos estudos coloniais. Eles têm seus próprios debates e cada um precisa imaginar como entrar neles e participar, começando do ponto em que eles estão.

\section{CF: Em várias ocasiões você escreveu so-} bre a teoria da prática. Agora, você anuncia um livro que vai se chamar Serious games, mas cujo subtítulo é "rethinking practice theory" [repensando a teoria da prática]. Por que intitular esse novo livro "serious games"?

"Serious games" é uma idéia de que realmente gosto bastante, e eu tentava trabalhá-la como um modo diferente de pensar sobre a teoria da prática e torná-la mais útil, tendo em vista algumas das controvérsias de que estávamos falando. Mas nos EUA, nas ciências sociais hard economia e ciência política - o quadro teórico dominante é a "teoria dos jogos". E toda vez que eu falava em público sobre "jogos sérios", eu era tão atacada e levava tanto tempo defendendo a expressão, que acabei desistindo. Agora, não a emprego mais como a expressão central do livro, porque não quero ter que lidar com toda essa bobagem.

CL: Mas qual era a idéia? O que a expressão quer conotar?

É sempre a mesma idéia básica, de tentar imaginar o que é preciso para fazer a teoria da prática dialogar com toda uma gama de outras questões, com as quais pessoas como Bourdieu não lidavam. Uma delas é a do poder, seja a dominação masculina, seja a colonial, a de raça ou a de etnicidade. Outra questão é a da história: como atualizar a teoria da prática com uma perspectiva histórica, o que concretamente faço em minhas monografias High religion, Life and death on Mount Everest, e também New Jersey dreaming, ${ }^{12}$ o livro sobre a turma de Ensino Médio com a qual me formei. São todos trabalhos históricos e usam como quadro geral a teoria da prática. A terceira questão é a da atualização do conceito de cultura, e meu argumento, na introdução desse novo livro, é de que não há conceito de cultura no Bourdieu clássico ou em Giddens. Sahlins é, em muitos aspectos, o mais útil para pensar simultaneamente a história e a cultura. Assim, ele tem um papel de bastante destaque nessa minha nova obra. De fato, eu acho o pequeno livro das metáforas históricas brilhante, ${ }^{13}$ mas Islands of history ${ }^{14}$ voltou a ficar muito estático, um estruturalismo estático. De certo modo, ele nunca chegou de fato a seguir os caminhos que abriu com Historical metaphors. Acho, então, que é possível abrir a teoria da prática de muitas maneiras, mas ainda penso que essa é a grade básica, a forma mais útil de pensar nas pessoas reais em relação à cultura, à história, ao poder - pessoas on the ground, na prática, mas articulando com um mundo mais amplo. Isto para a antropologia é perfeito, porque envolve tanto as pessoas reais quanto as estruturas e os sistemas mais amplos.

\section{CL: Quando você leu Bourdieu? Qual é a} sua relação com a obra dele?

Não estou certa de quando o li. Deve ter sido no início dos anos 1980, quando eu escrevia "Theory in anthropology since the $60 \mathrm{~s}^{\prime \prime} .{ }^{15} \mathrm{Eu}$ já tinha uma 
primeira versão das duas primeiras partes do artigo e não conseguia encontrar um final. E eu queria um final positivo, que apontasse para algo útil, em vez de ser apenas uma crônica de mudanças. Escrevi vários finais; não publiquei imediatamente o artigo. Eu estava também trabalhando em um texto sobre gênero, chamado "Gender and sexuality in hierarchical societies", com material polinésio. ${ }^{16}$ Alguém me contou que Marshall estava trabalhando em algo sobre gênero na Polinésia, então escrevi para ele. Foi quando ele me mandou o manuscrito de Historical metaphors, que ainda não havia sido publicado. Mas eu só o li pelos dados sobre gênero, que utilizei no artigo "Gender and sexuality in hierarchical societies", publicado em 1981. Bem, eu ainda procurava um final para "Theory in anthropology since the $60 \mathrm{~s}^{\prime}$, e lia coisas novas: Bourdieu, Foucault, talvez Giddens. De algum modo, eu me lembrei da discussão em Sahlins, a qual eu ainda não havia considerado teoricamente. Pensei: "tem alguma coisa acontecendo aqui em termos desse conceito de prática". Então, juntei-os e viraram a última parte do artigo, que foi publicado em 1984.

CL: Mas você afinal defendeu, no artigo, a abordagem de Bourdieu, não?

Eu não queria falar de Bourdieu apenas, embora ele obviamente fosse a figura principal, até por causa do título do livro: Esboço de uma teoria da prática. ${ }^{17}$ Mas eu não teria me interessado se fosse apenas um pensador. Eu tinha interesse à medida que podia falar de uma tendência que estava ocorrendo com uma série de teóricos: eu tinha Bourdieu, penso que também Giddens e, por incrível que pareça, eu via Foucault, na época, como um teórico da prática.

\section{CL: Por quê?}

Bem, devido à ênfase nas micropráticas como certa base de poder. Não é assim que a maioria das pessoas o vê, mas como era isto que eu estava tentando pôr em foco na época, pareceu-me que essa conexão também era possível. Assim, peguei Bourdieu, Giddens, Foucault e Sahlins e obtive então... uma tendência! O que havia ali, obviamente, era uma série de autores que faziam coisas diferentes, mas todos sustentando que para entender produção, reprodução e transformação da estrutura maior era preciso olhar para as práticas.

CF: Agora, se você tivesse de pensar em um símbolo-chave na teoria antropológica contemporânea, ainda seria a prática?

Não penso que haja apenas um símbolochave. Obviamente, não havia naquele período, tampouco. Houve contestações. Mas acho que é ainda mais o caso hoje; o campo me parece mais fragmentado. Não vejo uma escola predominante no momento.

CF: Você não diria que agência é o conceito-chave?

Acho que agência está se tornando, de certo modo, uma espécie de ímã da contestação. Quer dizer, insiste-se mais na questão da agência no campo dos estudos subalternos, em sentido amplo: feminismo, raça e etnicidade e parte dos estudos coloniais. Essa onda em torno da "agência" está agora associada principalmente ao trabalho que vem de baixo, com os pobres, com os que estão em várias situações de opressão - embora eu ache que deveria ser algo mais geral. Mas eu não diria que ela tem predominância na antropologia americana neste momento. 
Eu diria que é uma possibilidade em aberto, mas provoca muita resistência. As pessoas pensam que os americanos estão nessa de agência por serem americanos, mas como conceito, acredite, ela enfrenta ataques. Eu diria que a antropologia americana ainda é dominada pelo anti-humanismo, pela suspeita em relação ao agente.

CF: Eu ia justamente fazer uma pergunta sobre a relação entre o capitalismo tardio e a antropologia, baseada numa perspectiva bem diferente. No auge dos Estadosnação e da economia planejada, tivemos essa ênfase nos sistemas, na cultura, nas estruturas. Mas agora, no capitalismo tardio, falamos de flexibilidade, agência... Às vezes, parece-me que não estamos realmente refletindo sobre o mundo em seu estado atual, e sim adaptando a teoria antropológica a ele, de modo acrítico.

Na verdade, depende de quem você lê. Falando de modo geral, a literatura do capitalismo tardio, dentro da antropologia (considere os Commaroffs, Appadurai), fala das grandes forças. É bem estrutural. Fala de fluxos globais, grandes forças que se impõem sobre as pessoas. É uma leitura bastante foucaultiana do mundo, dominada por discursos totalizantes. Mesmo fora da antropologia, se você lê Jameson sobre o pós-modernismo, novamente é um tipo de grande sistema foucaultiano impondo-se às pessoas. Richard Sennett é um pouco diferente. Depende, portanto, do autor que se lê: os tratamentos mais marxistas do capitalismo tardio, as leituras mais foucaultianas, mais culturalistas... Há variações. Mas a onda da agência é quase como uma luta para manter sobre a mesa as questões da repressão e do poder, quando ninguém quer mais falar delas.

CF: Passemos ao seu trabalho mais recente, que tem a ver, afinal de contas, com o capitalismo tardio. Na introdução a The fate of culture, você diz que a cultura ainda é um conceito tremendamente efetivo e poderoso, e que para lidar com ele é preciso objetificar a sua própria condição cultural; que se deve inserir a análise cultural na paisagem maior das forças sociais e políticas etc. Você diria que seu trabalho sobre a sociedade americana é uma espécie de reflexividade densa?

Esta era a intenção ao trabalhar sobre os Estados Unidos. Especificamente, havia a idéia de que já era tempo de eu me voltar para minha própria sociedade e refletir sobre ela e sobre minha relação com ela, na qualidade de antropóloga e de nativa. Este era especialmente o caso em New Jersey dreaming, pois se tratava de meu universo. Mas o projeto Hollywood é também uma tentativa de pensar sobre a posição a partir da qual um antropólogo pode dizer algo significativo ao fazer pesquisa em contextos de poder e num universo no qual a cultura dominante tem impacto global.

CF: Mas por que Hollywood, especificamente?

Ainda que Hollywood não tenha agora o mesmo impacto que no passado, continua a ser uma das indústrias culturais mais influentes do mundo. De fato, eu estava interessada nisso desde antes de me mudar para Los Angeles, e essa mudança foi na verdade um lance de sorte.

CL: O seu projeto Hollywood também é sobre classe, não é? Como você vê o tema das classes nos EUA?

Acho que para mim as classes nos EUA são algo tão interessante porque, como afirmei no livro, finge-se que elas não existem. E também porque classe é uma categoria muito mais global alhures 
do que é para os americanos. Como de costume, os americanos tentam não pensar sobre o que todos os outros estão pensando. Quando comecei a conceber o projeto que veio a se tornar New Jersey dreaming, eu tinha uma idéia geral de que queria ter uma perspectiva crítica dos Estados Unidos, mas por onde começar?; que fazer? Minha impressão era de que, ao menos para a antropologia, classe era o tema intocado, não revelado, e pareceu-me importante trazê-lo à tona. Agora, em termos do mundo real, há esses argumentos de que classe importa cada vez menos. Talvez seja verdade, em algum sentido real, mas não acredito. É com certeza diferente em relação à definição marxista oficial: não vivemos num mundo de distinções simples entre donos de fábricas e trabalhadores nas fábricas; mas não creio que se possa parar de pensar em classes no mundo contemporâneo.

\section{CL: E de que modo entram as classes no seu projeto Hollywood?}

Todas as histórias de Hollywood começam com "depois do fim do sistema dos estúdios". O sistema dos estúdios entrou em crise no fim dos anos 1940, início dos 50. Os estúdios eram como senhores feudais: eram os donos da cidade. Tinham contratos de longo prazo com todos os astros e as estrelas e com os diretores que simplesmente trabalhavam para os estúdios e não tinham escapatória. Era, na verdade, escravidão, e acabou por ser desafiada. Mas naquela era, praticamente toda a produção cinematográfica saía dos próprios estúdios. A MGM, a Warner Brothers diziam: "Muito bem, este ano precisamos produzir um número $\mathrm{x}$ de filmes. Vamos fazer três comédias, três tragédias e três filmes de suspense". Era como ter o baralho nas mãos, eles podiam fazer tudo o que quisessem. O sistema dos es- túdios desmorona e passa a ser ilegal em meados do século XX. E o que o substitui são muitas pequenas produtoras. $\mathrm{O}$ que venho fazendo é dirigir o foco para essas produtoras. O que se evidenciou para mim como algo interessante é que a maioria dos produtores é bem de classe média alta, são muito instruídos. Educação de luxo, em instituições caras e de prestígio, ${ }^{18}$ famílias ricas, com muito capital material e cultural. Eis a classe dos administradores profissionais. Se olharmos para essas produtoras, que são a principal fonte daquilo que sai dos estúdios - exceto pelos supermegalançamentos - existe basicamente uma categoria específica de pessoas que fornece para os EUA e para o mundo aquilo que é hoje o filme hollywoodiano. Este, portanto, vem de um nicho de classe, o que é completamente diferente dos estúdios de antigamente, pois os chefes dos estúdios, no início de Hollywood, eram imigrantes judeus, muitos deles sem instrução, ou seja, nada de capital cultural! Eram iletrados, não tinham ido à escola, muitos eram analfabetos. Foram eles que - era uma vez, há muito tempo - fizeram os nossos filmes. Agora, quem faz os filmes é o seu amigo próximo, alguém que você, eu, nós todos conhecemos, é gente que foi às mesmas escolas que nós. É a nossa classe, a classe do saber. Enfim, é aí que se situa a questão da classe no projeto Hollywood.

\section{CF: E são eles que estão produzindo a} cultura pública que os antropólogos vão analisar.

Sim. Estão produzindo o que funciona hoje como a cultura para a maioria das pessoas. É daí que eles extraem seus quadros de referência - eles sempre vieram da cultura pública.

CF: Eles têm, portanto, uma posição especial de agente no sistema cultural. 
Com certeza. E, mesmo assim, eles ainda são como todos os agentes: há restrições. O sistema dos estúdios já não vigora, mas os estúdios ainda existem e dominam o financiamento dessas empresas: elas precisam procurar os estúdios para financiarem os filmes, e formam vários tipos de parceria. Mas até os executivos dos estúdios são os mesmos, somos nós. Quero dizer que são duas frações da mesma classe.

CF: Gostaria de fazer uma pergunta sobre a diferença entre a antropologia crítica e a etnografia. Em seu artigo "Generation $X^{\prime \prime},{ }^{19}$ você diz que teve a impressão de que essas pessoas de classe alta não eram a Geração X, mas aparentemente eles se sentiam como tal. Aqui temos a regra cardeal da etnografia: os informantes têm sempre razão. Mas, ao mesmo tempo, para uma antropologia crítica at home, é fundamental a idéia de que o analista tem uma posição privilegiada e é capaz de lançar um olhar crítico que vai além da autoconsciência. Como você concilia estas duas exigências contraditórias?

Creio que há uma diferença entre considerar as percepções das pessoas acerca de sua própria situação como falsa consciência, num sentido marxista, e considerá-las como algo que se deve levar em conta. Em outras palavras, no quadro da falsa consciência, elas seriam descartadas: "Eles pensam isso, mas na verdade é aquilo. Eles se vêem dessa forma, mas é claro que estão errados. A verdade é outra". Ao passo que num quadro weberiano (ou qualquer outro quadro mais sofisticado de interpretação do que as pessoas dizem ou pensam), você tem de levar em conta as próprias percepções das pessoas. A interpretação que você faz não deve negá-las, mas compreendê-las. É preciso que haja algum quadro interpretativo que inclua as percepções delas, e não as descarte.
Esta é a diferença. Assim, é claro, estou assumindo uma perspectiva crítica, a qual não afirma que as pessoas estão corretas em última análise. Mas diz que é preciso ouvir. A interpretação tem de incluir as percepções das pessoas, não deixá-las de fora.

CF: Não é isto que a pesquisa de campo de longa duração nos permite fazer?

Certo. E é isto que deve ser feito. Apesar de todas as mudanças, é isto que estamos fazendo. O que há para fazer além de compreender por que eles pensam aquilo que pensam?

\section{CF: Considerando retrospectivamente} o seu esforço intelectual, há algo que você não tenha feito e ainda gostaria de fazer?

O projeto Hollywood pretende ser isso, pretende tentar, de modo relativamente ambicioso, tomar algo como uma máquina de cultura e realmente pensar sobre o modo como a cultura é produzida. Mas não é só isso, eu tenho um pequeno projeto pessoal por trás do projeto Hollywood, pois espero produzir pessoalmente dois documentários sobre a cultura americana em geral, sobre os filmes de Hollywood, sobre minha própria vida.

\section{CF: Por que documentários?}

Eu adoro documentários. Sempre adorei. É a versão americana, ou talvez universal, da etnografia. Os documentários são aquilo que as pessoas fazem a partir daquele mesmo impulso que utilizamos para fazer etnografia. Mas os documentaristas não precisam ser treinados como etnógrafos, não precisam ter nenhum tipo de instrução formal ou qualquer outra coisa. É, portanto, de algum modo, uma etnografia universal. 


\section{Notas}

${ }^{1}$ Ortner, Sherry (org.). 1999. The fate of culture: Geertz and beyond. Berkeley: University of California Press.

${ }^{2}$ Robert McCormick Adams.

${ }^{3}$ Schneider, David. 1968. American kinship: a cultural account. Chicago: The University of Chicago Press.

${ }^{4}$ Distribuído no Brasil com o título A primeira noite de um homem.

${ }^{5}$ Distribuído no Brasil com o título Uma rajada de balas.

${ }^{6}$ Ortner, Sherry. 1974. "Is female to male as nature is to culture?" In: Michelle Rosaldo \& Luise Lamphere (orgs.), Woman, culture and society. Stanford, CA: Stanford University Press. pp. 67-87.

${ }^{7}$ Ortner, Sherry. 1978. Sherpas through their rituals. Cambridge: Cambridge University Press.

${ }^{8}$ Ortner, Sherry. 1989. High religion: a cultural and political history of sherpa buddism. Princeton: Princeton University Press.

${ }^{9}$ Ortner, Sherry. 1999. Life and death on Mount Everest: Sherpas and himalayan mountaineering. Princeton, NJ: Princeton University Press.

${ }^{10}$ Franchetto, Bruna. 1996. "Mulheres entre os Kuikuro". Revista Estudos Feministas, 1:35-54.

${ }^{11}$ Ortner, Sherry. 1996. Making gender: the politics and erotics of culture. Boston: Beacon Press.
${ }^{12}$ Ortner, Sherry. 2003. New Jersey dreaming: capital, culture, and the class of '58. Durham, NC: Duke University Press.

${ }^{13}$ Sahlins, Marshall. 1981. Historical metaphors and mythical realities: structure in the early history of the Sandwich Islands Kingdom. Ann Arbor: University of Michigan Press.

${ }^{14}$ Sahlins, Marshall. 1985. Islands of history. Chicago: University of Chicago Press.

${ }^{15}$ Ortner, Sherry. 1984. "Theory in anthropology since the sixties". Comparative Studies in Society and History, 26(1):126166.

${ }^{16}$ Ortner, Sherry. 1981. "Gender and sexuality in hierarchical societies: the case of Polynesia and some comparative implications". In: Harriet Whitehead \& Sherry Ortner (orgs.), Sexual meanings: the cultural construction of gender and sexuality. New York: Cambridge University Press.

${ }^{17}$ Bourdieu, Pierre. 1972. Esquisse d'une théorie de la pratique. Paris: Points.

${ }^{18}$ No original: "Fancy educations, Ivy League educations, wealthy backgroun$\mathrm{ds}$, full of material and cultural capital". Ivy League é um conjunto de instituições tradicionais de ensino muito prestigiosas do leste dos EUA.

${ }^{19}$ Ortner, Sherry. 1998. "Generation X: anthropology in a media-saturated world". Cultural Anthropology, 13(3):414440 . 